\title{
The irony of it all
}
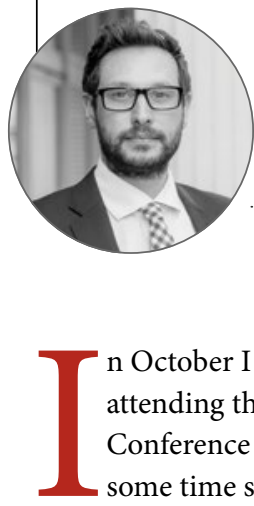

\section{David Westgarth}

Editor, BDJ in Practice

I n October I had the pleasure of attending the $\{$ my $\}$ dentist Clinical Conference in Liverpool. It's been quite that kept my attention like that one did, and the highlight for me was a panel session featuring former Chief Dental Officer for England, and Non-executive Director at $\{$ my dentist, Barry Cockcroft.

In this panel session - and I tweeted it at the time, Cockcroft said: 'Government only takes dentistry serious when it becomes a problem. With pictures of people queuing around the block to see a dentist, I think we're getting to that point?

Let's take some time to digest that comment before analysing the current dental landscape and some of the issues NHS dentistry across England and Wales faced in 2019 alone, never mind the last decade.

For starters, here are a selection of headlines from the BDA's media team from this year alone:

' 1 million new patients unable to access NHS dentistry, as recruitment and retention crisis mounts' ${ }^{1}$

'NHS dentistry: $£ 12$ slashed from care for every man, woman and child in England since $2010^{\prime 2}$

'Postcode lottery of decay demands real investment in prevention's

'NHS charges increases covering cuts and undermining prevention'

'75\% of NHS dental practices now struggling to fill vacancies.'

These are all before the clocks went forward in March. I could go on, but you get the picture.

For those new to the profession, Cockcroft was appointed Deputy Chief Dental Officer for England in November 2002 and appointed as Chief Dental Officer in 2006 before stepping down in 2015 . He had been involved in piloting a new system of dental remuneration since 1997 prior to these appointments, so it's fair to suggest that for many dental professionals who have worked through that era - and for plenty in attendance at the conference - the irony of hearing the former CDO suggest the government is only now waking up to the problems faced by practitioners every day was not lost on them.

For at the heart of those five headlines lies the rubble of the 2006 dental contract. As you may imagine, that particular quote set tongues wagging, and sent some jaws to the floor in shock. 'How could he suggest such a thing? He must have a short memory' was one attendee's response. Others weren't clean enough to print.

Without putting too fine a point on it, NHS dentistry is in crisis. The BDA has worked tirelessly to get that message onto the front pages and into the thought streams of politicians. Many practitioners are leaving the profession purely because the demands placed upon them by the 2006 contract are simply too much for them to cope. Research carried out by the BDA suggests stress at all levels in dentistry - including students - is on the increase. Practice owners in England and Wales have seen their real incomes fall by $30 \%$ since 2008/9. Patients are having to travel 90 miles in England and Wales just to find an NHS dentist, an issue $\{$ my $\}$ dentist themselves are culpable of making worse - a point CEO Tom Riall made clear in his opening speech.

In an editorial, Cockcroft himself wrote: 'Most people have now forgotten (or may not even be aware of) the vast areas of the country that had no access to NHS dental services in 2002 and this situation was continuing to deteriorate. $^{6}$

Maybe I've missed something, but how can we be getting to 'that point', as mentioned at the Conference, yet there is the suggestion that things have improved? Surely the two cannot go hand-in-hand? To glibly suggest the problems are at the end of a cycle in the profession rather than the result of decisions made prior to 2006 maybe isn't a message we want to hear. The reality is the 2006 contract from day one plunged the profession from one downward spiral into a new one in a different atmosphere.

It is almost 18 years later and vast areas of the country have no access to NHS dental services. It is almost 18 years later and patients cannot afford the access that they do have. It is almost 18 years later and dentists have not seen pay increases in line with inflation.

Maybe we're at that point due to UDA targets, clawback, low morale, a depleting workforce, and maybe we're at that point because these are things the 2006 contract has facilitated and festered since its introduction.

As 2020 begins and we all look towards the introduction of a new dental contract, this remark is a timely reminder of how the BDA works and will continuously work to improve the working conditions of every member. Contract Reform is becoming tantalisingly closer, and as the evidence base grows on how the blends are performing, so will the BDA's voice on these matters to ensure the mistakes of 2006 are not repeated.

\section{References}

1. British Dental Association. News release: 1 million new patients unable to access NHS dentistry, as recruitment and retention crisis mounts. Issued 2 February 2019. Available online at: https://bda.org/news-centre/ press-releases/Pages/1-million-new-patients-unable-toaccess-NHS-dentistry.aspx (Accessed December 2019).

2. British Dental Association. News release: NHS dentistry: $£ 12$ slashed from care for every man, woman and child in England since 2010. Issued 9 February 2019. Available online at: https://bda.org/ news-centre/press-releases/12-pound-slashed-fromdental-care-for-every-man-woman-and-child-inengland-since-2010 (Accessed December 2019).

3. British Dental Association. News release: Postcode lottery of decay demands real investment in prevention. Issued 6 March 2019. Available online at: https://bda.org/news-centre/press-releases/ postcode-lottery-of-decay-demands-real-investmentin-prevention (Accessed December 2019).

4. British Dental Association. News release: NHS dental charge increases covering cuts and undermining prevention. Issued 11 March 2019. Available online at: https://bda.org/news-centre/press-releases/Pages/NHScharges-increases-covering-cuts-and-underminingprevention.aspx (Accessed December 2019).

5. British Dental Association. News release: $75 \%$ of NHS dental practices now struggling to fill vacancies. Issued 16 March 2019. Available online at: https://bda.org/news-centre/press-releases/75per-cent-of-nhs-dental-practices-now-struggling-tofill-vacancies (Accessed December 2019).

6. Cockcroft B. Reflections on leading change. Fac Dent J 2018; 9: 10-13.

https://doi.org/10.1038/s41404-019-0272-4 